\title{
DISABILITY AND MORAL RESPONSIBILITY
}

\author{
Simo Vehmas \\ University of Jyväskylä
}

\begin{abstract}
This article offers an introductory analysis of the philosophical and empirical considerations having to do with the significance of psychopathy, intellectual disability and ADHD regarding one's moral responsibility. Moral responsibility comes in degrees and is ultimately determined on social grounds. Whether a certain diagnosis and its underpinning neuro-cognitive impairment affects one's cognitive, emotional and moral conduct, depends also on social and relational factors.
\end{abstract}

Keywords: accountability, attributability, ADHD, intellectual disability, moral responsibility, psychopathy

DOI: $10.3176 /$ tr.2011.2.04

\section{Moral responsibility}

Ascribing moral responsibility to someone means that he is worthy of praise or blame for his actions and omissions. Moral responsibility has traditionally been seen as a distinctive feature of persons that differentiate them from other creatures. Consider, for example, that your careless cat accidently breaks your financially and emotionally treasured ceramic sculpture. The cat was undoubtedly causally responsible for the destruction of your sculpture which may very well make you feel regret and even anger. But to feel moral indignation would be clearly unwarranted because your cat is not a moral agent, a being that is capable of acting with reference to right and wrong. On the other hand, if your sculpture was broken by your presumably right-minded neighbour who was envious of your sculpture, and intentionally broke it in order to hurt you, your resentment and moral indignation would be appropriate. Thus, judgments about individuals' moral responsibility relate to views about, first of all, their relevant capacities to evaluate reasons for acting, secondly, about their possibilities to act freely, and thirdly, about possible excusing factors (Eshleman 2009, Fischer and Ravizza 1998:1-2). 
Aristotle was the first to formulate the general conditions of moral responsibility. In Nicomachean Ethics (1998:1109b30-1111b5), he explains that it is only agents who possess a capacity for choice that qualify as moral agents, and who are properly subject to ascriptions of responsibility. A proper choice, on the other hand, results from the kind of deliberation that expresses the agent's conception of what is good. Choice is voluntary but not the same thing as the voluntary for the latter is a broader category: "For both children and the lower animals share in voluntary action, but not in choice, and acts done on the spur of the moment we describe as voluntary, but not as chosen" (Aristotle 1998:1111b5-10).

For Aristotle, there are two ways in which an agent can fail to be morally responsible: ignorance and force. Ignorance can mean several things: "A man may be ignorant, then, of who he is, what he is doing, what or whom he is acting on, and sometimes also what (e.g. what instrument) he is doing it with, and to what end (e.g. he may think his act will conduce to someone's safety), and how he is doing it (e.g. whether gently or violently)" (Aristotle 1998:1111a3-5). Another form of condoning condition is force. Responsibility may be undermined by force with the following kinds of paradigmatic cases: irresistible psychological impulses, brainwashing, hypnosis, or direct manipulation of the brain. Thus, moral responsibility requires two conditions. Firstly, the agent is responsible only if she both knows the particular facts surrounding her action, and acts with the proper sort of beliefs and intentions. This condition can be termed as 'epistemic condition'. The second condition related to force specifies that the agent must do what she does freely, not as a result of undue force. That is, she must be able to control her behaviour in order to be morally responsible for it. This condition is the 'freedom-relevant condition' or the 'control condition' (Fischer and Ravizza 1998:12-13).

Responsibility can also be conceptualized in terms of attributability and accountability. In the sense of attributability the credit or fault of agent's actions is related to his or her self. Thus, if an agent's actions result from his freely chosen ends, they belong to him and can properly be attributed to him. To be responsible for one's actions in the sense of being accountable presupposes responsibility in the sense of attributability. Moral responsibility as accountability entails a warranted belief in an agent's capability to govern her actions in a way that they accord with social norms and expectations. Moral responsibility as accountability is a social notion that implies a full membership in the moral community and that the individual is praiseworthy or blameworthy for her actions (Eshleman 2009, Fischer 1999). Moral responsibility understood as a social notion is based on P. F. Strawson's (1962) influential account where he is more concerned about people's reactive attitudes to moral acts than about the metaphysical conditions of being responsible. Thus, our views of holding people morally responsible are necessarily intertwined with interpersonal relationships; what acts are regarded reflections of, for example, an agent's good will or ill will, derive their meaning from agreements regarding proper ways of being and acting in these interpersonal 
relationships. Strawson's account has naturally raised various objections but on the whole, his view about the social nature of moral responsibility seems plausible.

In this article, I will concentrate on discussing the control condition of moral responsibility in the light of three very different kinds of cognitive disabilities, namely, psychopathy/antisocial personality disorder, mild intellectual disability and ADHD. What unites these conditions (assuming they are intrinsic conditions or properties of individuals) is that they can all be seen to question one's moral responsibility and moral agency. People with these kinds of disabilities and disorders can, in other words, be seen to be either just outside the moral community or just inside it: "They are, we might say, morally responsible sometimes and in some ways" (see Shoemaker 2010:439). So, the main question of this article is: may psychopathy, mild intellectual disability or ADHD exempt one from moral responsibility?

\section{Badness as madness?}

Consider a psychopathic criminal, an adult person of average intelligence who has no emotional reaction to hurting other people. He says that he knows that hurting and killing other people is in principle wrong but he just does not care; he is not capable of becoming emotionally involved with the suffering and misery he has caused to other people. This kind of person is considered to be a psychopath; a person who typically disregards other people's feelings and well-being, and who has failed to develop true moral sensitivity, conscience, understanding, and motivation (American Psychiatric Association 2000, Kennett 2006, Shoemaker 2009). What about those individuals, who know when they have done a bad thing, as it were, but whose limited intellectual capacity is such that it is uncertain whether they are appropriate targets of praise or blame like moral agents are? Intellectual disability is characterized by significant limitations both in intellectual functioning and in adaptive behaviour, which covers many everyday social and practical skills. Adaptive behaviour comprises three skill types: conceptual skills (e.g. language, money, time, and self-direction), social skills (e.g. interpersonal skills, social responsibility, self-esteem, and gullibility), and practical skills (e.g. activities of daily living, occupational skills, healthcare, safety) (American Association on Intellectual and Developmental Disabilities 2010). And finally, what should we think about the significance of ADHD regarding one's moral responsibility? ADHD includes an untypically frequent and severe pattern of inattention and/or hyperactivity or impulsivity compared to other individuals at a comparable level of development. Individuals with ADHD are commonly observed as having reduced capacity, for example, to pay attention, inhibit their impulses, and regulate their own behaviour relative to rules, time, and the future (Barkley 2006:77-83, Cooper 2001).

Are all these three diagnoses factors that can reasonably be seen to restrict one's free will and responsibility? Traditionally, various psychiatric conditions 
have been seen to exempt people from culpability because arguably they are diseases that make us act in ways that are out of our control. Thus, it can be argued that the acts of someone with, say Narcissistic Personality Disorder or Antisocial Personality Disorder are merely involuntary reactions that stem from his or her brain functions; they are a bit like a sneeze or a seizure and, therefore, (more or less) forgivable (Arpaly 2005:290-291, see also Glannon 2005, Kennett 2002, Schroeder 2005). One's culpability for one's actions depends whether one's mental make-up (or excusing 'disorder') actually is an exempting factor. Psychopaths are seen by many moral psychologists relevantly impaired in the sense that they lack the possession of moral concepts and the capacity to apply them. In other words, psychopaths are amoral beings lacking in moral concern and sometimes even overflowing with ill will, and because of this, they are not morally responsible moral agents (Fine and Kennett 2004, Kennett 2002). Some scholars, however, take a somewhat opposite view. Maibom (2008), for instance, argues that Antisocial Personality Disorder is specifically a moral disorder. In her view, "psychopath's badness is his madness" and that "whereas we may excuse people for being $\mathrm{mad}$, it would be utterly paradoxical to excuse people for being bad" (Maibom 2008:168). Maibom thus argues that Antisocial Personality Disorder is not a medical disorder as much as a moral disorder. Likewise, and with greater confidence, I think, one can say that intellectual disability and ADHD are not medical disorders as much as social 'disorders'.

In jurisdiction, psychopathy is often thought to be an aggravating rather than a mitigating factor in determining criminal responsibility (Fine and Kennett 2004). Individuals with intellectual disabilities, on the other hand, are often judged to have the kind of mental 'defect' that mitigate their liability. In the United States, for example, in most states that still condone death penalty, the execution of individuals with intellectual disabilities is outlawed as an example of cruel and unusual punishment (Weithorn 2008). Diagnoses such as ADHD are increasingly also seen relevant regarding responsibility. For example, a pupil in Wisconsin vandalized two elementary schools with his two fellow pupils causing 40,000 dollars worth of damage, avoided expulsion as a 'disabled student' after his mother had acquired a private psychologist's statement that her son had ADHD. The two other students only escaped expulsion by withdrawing from the school. According to the court's verdict ADHD invalidated the pupil's free will and accountability (Tait 2006:83).

Thus, a condition may sometimes exempt one criminally, but not morally, and the other way round. This can be explained with the distinction between responsibility as attributability and accountability. For example, psychopaths are usually held criminally responsible because their harmful actions are properly attributable to them; they intentionally committed the harm they are accused of, and knowingly broke the law due to the fact that they are capable of understanding and applying legal norms. In other words, most psychopaths comprehend which actions are deemed illegal and are thus regarded warrant for legal blame. But they are not held morally responsible because they are not accountable for their 
actions; they usually don't have the emotional capability to appreciate and respond to the invitation to feel what one has done to another. David Shoemaker argues that to be accountable requires that one is able to "(a) recognize and appreciate the distress associated with injuries and harms for what it is; (b) understand what it is like for the injured or harmed party; and (c) feel what the injured or harmed party feels in being so affected" (Shoemaker 2009:448). So, according to Shoemaker, accountability does not require intellectual capacity to apply abstract moral principles but it does require the emotional capacity for empathy. Psychopathy characteristically prevents one from feeling for others, whereas intellectual disabilities and ADHD do not.

Thus, being morally responsible in the attributive sense requires the kind of cognitive competence that enables one to comprehend the nature of moral concepts, and how they might apply to one's own concrete deliberations and actions; if you are able to understand how various moral or legal norms apply to your actions, your actions are attributable to you. Being morally responsible in the accountable sense, however, requires the capacity to relate to others emotionally; one needs to feel what one makes others feel and to engage emotionally with others. In practice, it is pointless to hold the kind of person accountable who is incapable of truly appreciating this sort of emotional address (Shoemaker 2009).

Shomaker's argument and usage of the distinction between attributability and accountability may seem a bit strange; even though a person could not feel empathy for others, his actions could still be attributed to him if they express his identity and what he stands for (Watson 1996). But on the other hand, it does make sense to argue that the inability to feel empathy is morally relevant. Psychopaths are, by definition, emotionally and morally numb to the extent that they may be held criminally responsible albeit not being proper targets of moral blame. The situation is completely different for individuals with intellectual disabilities and ADHD whose disability does not prevent them from engaging in the relevant empathy with others.

\section{Intellectual disability and (collective) agency}

Some individuals may be eligible in fewer instances for assessment of blame or praise than others. Shoemaker (2009) suggests that individuals with mild intellectual disabilities are eligible for accountability primarily just by those with whom they already find themselves emotionally engaged, such as family, friends and caregivers. The reason for this, he argues, is that "their developmental capacities have been limited to the stage of concrete operations" (Shoemaker 2009:455) and, therefore, they are unable to appreciate abstract principles about mutual recognition and accountability among fellow members of the moral community. Shoemaker thus argues that due to their cognitive capacities, persons with mild intellectual disabilities are able to appreciate only the concrete appeals from those they care about while often being unable to respond emotionally and 
morally in a proper way to the appeals of strangers. This notion could well be applied to most people because it appears to be a part of human condition that we tend to favour morally beings emotionally close to us (e.g. Williams 2006). However, Shoemaker's suggestion, which uncritically relies on Piagetian notion of 'normal' development, is empirically clearly unfounded. It most certainly contradicts the personal experience of many people with mild intellectual disabilities who, as represented in the self-advocacy movement, emphasize their shared humanity with fellow citizens (e.g. Goodley and Rapley 2001, 2002, Taylor 1996).

It has traditionally been assumed that the potential of submissive, willing-toplease acquiescence is powerful among people with intellectual disabilities; they are overly disposed to agree and say 'Yes' to virtually any question which implies that their answers are generally invalid. They are, allegedly, prone to bow to someone else's will and thus exhibit a low level of agency. This view that seems rather bizarre to anyone who has had close relationships to people with intellectual disabilities, includes various problems.

First of all, the traditional conception of disability is one-sidedly based on individualistic and naturalistic assumptions about the nature of the phenomenon that, ultimately, result in labelling and stigmatization. Intellectual disability, or any other psycho-medical category, is not merely the result of an organic difference but also, and to a large extent, it is a social and cultural construct. Categorizations on the grounds of impairments are based on normative expectations of how human beings ought to develop and what kind of beings they should develop into (Vehmas and Mäkelä 2009). People with intellectual disabilities do not fit into these expectations and they are labelled deviant. This labelling carries with it a stigma that is not merely a difference, "but a characteristic that deeply discredits a person's moral character" (Taylor and Bogdan 1989:23). Labels also tend to create self-fulfilling prophecies; people classified in a certain way tend to conform to or grow into ways that they are described (Hacking 1995:21). Thus, intellectual disability is a very complex phenomenon that cannot be reduced simply to the 'stage of concrete operations'. There are various other, mainly social, factors that affect the social, emotional and moral competence of individuals with intellectual disabilities.

Secondly, individuals with intellectual disabilities are often seen as less accountable than others due to a simplified, individualistic conception of competence and agency where self is understood as a sum total of one's individual characteristics. Alternatively, one's competence, identity and agency can be conceptualized relationally, collectively, and in terms of interdependence. For example, Goodley and Rapley $(2001,2002)$ have offered an illuminative empirical analysis of an 'expanded identity' where individuals' competence is not reduced merely to their individual attributes but to their social networks. Goodley and Rapley report of cases where a person's perceived lack of independence and competence provides a catalyst for other individuals with intellectual disabilities to act and compensate the weaknesses of that person. They argue that self-advocacy groups of people with intellectual disabilities can contribute to the development of collective self-empowerment and 
decision-making of their members where the 'dependent' and 'incompetent' individual is an essential cog in the mechanism that brought about such a development. Thus, selfhood, independency, freedom, or moral responsibility can meaningfully, and in line with Strawson's account, be understood relationally, in terms of social association and community. The significance of accepting relationships and environments should also be considered in this context. Taylor and Bogdan (1989:27) define accepting relationships as long-standing and characterized by closeness and affection in which the disability does not have a stigmatizing, or morally discrediting, character in the eyes of the so-called normal people. The more accepting environment individuals with intellectual disabilities are surrounded by, the more chances they have for collective self-empowerment and 'expanded identity' and, consequently, the more chances they have for exhibiting their agency and moral responsibility.

Thirdly, the assumed acquiescence of people with intellectual disabilities is often a result of bias and professional practices that promote a power asymmetry in the encounters between professionals and their clients. Rapley and Antaki (1996), for example, have demonstrated how 'acquiescence bias' among professionals and policy-makers who conduct interviews and questionnaires with people with intellectual disabilities, has often resulted from test situations that leave very little room for the client's agency and subjective voice. People with intellectual disabilities, as people in general, tend to be more competent and active with those people with whom they have a long-term, intimate relationship than they are with those whose interactions with them are more occasional and clinical. Interview and test situations are often the basis for the conceptions about the competence of people with intellectual disabilities, and also the basis of decisions about how and where these people will live, what training or education they will receive, the kinds of interpersonal relationships they will experience, and whether they will live or die (Goode 1984). The problem with these short-term clinical interactions is that they tend to work on the basis of quite rigid conventions of 'proper' communication and overlook untypical ways of communication with the result that the subjective voice of the client can be misinterpreted or left unheard.

To conclude, the assumption that people with intellectual disabilities are generally submissive and cannot be expected to express their views validly, is overly simplistic as well as empirically questionable. Therefore, it is also questionable to claim that their capability to respond properly to the emotional and moral appeals of strangers is poor. Surely, people with intellectual disabilities have to overcome cognitive limitations that may affect their moral agency. But it would be hasty, to say the least, to make any general normative conclusions about their moral agency and responsibility simply because "their developmental capacities have been limited to the stage of concrete operations", as Shoemaker (2009:455) does. 


\section{ADHD and the moral responsibility of professionals}

There is now a huge literature written from within various disciplines (i.e. medicine, neurobiology, psychology, pedagogy) that takes ADHD to be an objective phenomenon, or more precisely, an objective pathology. According to this view ADHD is a name for some people's misbehaviour that is rooted in human physiology (Cohen 2006, Tait 2005, 2006). Numerous accounts suggest that ADHD is a matter of a physiological, objective fact. This view seems quite peculiar since all classifications about people and their behaviour are necessarily determined socially and institutionally. Even if scientists managed one day to explain comprehensively, for example, the physiological causes of 'hyperactivity', it would still remain ontologically a social phenomenon that is determined socially. Phenomena such as (hyper)activity and (in)attention are not physiological facts that exist independently of cultural interpretations and representations. Rather, as phenomena and as concepts, they are developed and defined by people to describe certain other people's behaviour, possibly caused by physiological factors.

Yet, the attraction of ADHD diagnosis for many children, and for their parents, is understandable because when their behaviour is seen to be based on illness-like condition, their problems are recognized as real, and perhaps as painful and debilitating as illnesses can be, and as unlikely to be wished away (Arpaly 2005). Thus, the diagnosis in a way separates person's problematic behaviour from her identity with the result that the individual herself as well as her parents are absolved from responsibility. The individual's 'misconduct' cannot, according to the medical view, be explained by his or her bad moral character nor is it caused by poor parenting (Tait 2005, 2006). The power of dopamine transporter is seen to be so overwhelming that exercises of self-control or devoted parental love cannot conquer it. Unsurprisingly, sometimes ADHD has been seen to question one's moral responsibility.

This is the kind of logic that the mother, who wanted her son to be absolved from responsibility for vandalizing school buildings, probably had in mind. However, suppose that this boy had artistic gifts and often experienced long, excited states of inspiration accompanied with hyperactivity, tantrums and behaviour that could be depicted manic, but which resulted in good art. If art is central to the life and identity of this young man, telling him that his state of inspiration is actually a mild form of mania and results from his ADHD, he (and his mother) would probably feel insulted. That would be a natural reaction to being told that the meaningful activities of your life are like sneezes or seizures. Thus, the fact that someone has a neuropsychological/psychiatric diagnosis does not automatically mean that he or she is not blameworthy or praiseworthy (Arpaly 2005).

It should be remembered that the misconducts of those with ADHD diagnosis are not usually very grave, nor necessarily harmful to other people. The significance of the 'epistemic condition' and the 'freedom-relevant condition' of moral responsibility is ultimately related to the nature and moral weight of the 
offence: intoxication can be seen morally and legally as an excusing factor in the case of public urination but not in the case of homicide. Also, the misconduct of individuals with ADHD is, to a large extent, linked to the various institutional practices and conventions; behavioural disorders like ADHD seem, after all, "to be discovered almost exclusively in areas where they pose a threat to effective social and educational management" (Tait 2006:88). In other words, school especially is the kind of institution which sets very strict standards of social competence to its pupils with the result that, for example, shyness or impulsiveness are highly undesirable character traits from teachers' perspective because such a pupil may require a special attention, and from an individual pupil's perspective because these features can be a hindrance to his school success. Increasingly, such character traits are now likely to be explained in terms of disorder. The current school system appears to require an official and scientifically legitimized label until the pupil's individuality is recognized, in one way or another (e.g. individualized tuition). A common-sense empathetic stand or the usage of moral imagination apparently does not meet the requirements of professionalism.

Despite the fact that uncontrolled impulsivity and hyperactivity may be morally exempting factors, diagnoses such as ADHD are problematic when making judgments about one's moral agency and responsibility simply because the diagnosis itself, and the phenomenon it tries to convey, are ambiguous and open to various interpretations. Moral responsibility comes in degrees and whether a certain condition is a mitigating factor depends on the nature of that condition as well as on various contextual factors. Perhaps the prime ethical issues related to ADHD and other 'behavioural disorders' in school context are matters of professional ethics rather than the morality of 'behaviourally disordered' children's conduct and character. Teachers and other professionals working with these children ought to acknowledge the problems and risks related to neuropsychiatric diagnosing. Traditionally, school organization has focused on analyzing pupils' conduct and character because it has been assumed that classroom management problems have been caused by pupils' disruptive behaviour which, for one, originates in their character.

Medicalization of student misbehaviour and unchallenged diagnosing practices label the student as the primary source of, for example, classroom management problems. Diagnoses such as ADHD, however, often offer one-sided and superficial information about individuals with that diagnosis. ADHD, 'behavioural disorder' and other diagnostic categories create social order and arguably make people more controllable and manageable. In addition, these diagnoses may well be sincere attempts to offer psychologically well-grounded descriptions about some children and their core of being. But at the same time, teachers should recognize the contextual nature of student misbehaviour and ask themselves to what extent the need to diagnose, for instance, ADHD is based on their subjective experience when they feel that some pupils are tiresome and too demanding. Diagnoses may absolve teachers and school organization too easily from responsibility regarding disruptive behaviour. 
Terms like 'student with behavioural disorder' explain the problems in social interaction in terms of mental qualities of 'disordered' pupils. The term portrays the phenomenon and certain individuals in a way that one is inclined to believe that these students would be disruptive and out of order regardless of the social and educational context. This kind of conclusion would be, of course, completely silly because ADHD and behavioural disorders in general cannot take place in a vacuum: problems in social life take place in social interaction. 'Behavioural disorder', or any other social phenomenon, requires the existence of more people than just one. This is probably not a very profound observation but that is exactly the point with ADHD, behavioural disorders in general, and the ways they should be taken into consideration in education: careful psychological analyses may be useful in the execution of individualized tuition and class room management, but they can become self-defeating if plain common sense is forgotten.

\section{Conclusion}

Moral responsibility is an extremely complicated concept and phenomenon. In this article, I have intentionally ignored the metaphysical debates about the nature of the phenomenon and have, instead, aimed to introduce and enlighten some of the philosophical issues related to the significance of ADHD, intellectual disability and psychopathy regarding one's moral responsibility. Unsurprisingly, I have not offered a strong normative position that would exempt individuals with these disabilities or disorders from moral responsibility, any more than I would have definitively ascribed responsibility to them. It is safe to argue that moral responsibility comes in degrees and that this fact concerns all people despite their possible disabilities or mental disorders. It is quite impossible for any of us to be equipped with the kind of knowledge, mental abilities, as well as personal and social freedom so that the epistemic and control conditions of moral responsibility would always hold true for us. Similarly, it would be wrong to make hasty normative conclusions on the grounds of a diagnosis or label which may capture only some dimensions of a person's self. This applies especially to intellectual disabilities and ADHD, which are the kinds of diagnoses that may affect individuals (with the allegedly same conditions) and their cognitive, emotional and moral 'capabilities' in various ways.

Diverse empirical understanding seems of crucial importance when making judgments about the moral significance of various disabilities and disorders. The history of disability makes an example of one-sided and simplistic individualistic conceptualization that has in its part often had negative, even tragic, consequences to the lives of people with impairments (e.g. Barnes et al. 1999, Garland 1995). A clinical and so-called objective approach to disability has too often resulted in downright prejudiced depictions of disability. Having said that, it is important to note that some neuro-cognitive impairments, for example, have direct implications to one's emotional and moral responses (Blair et al. 2006, Cullity 2006, Prinz 
2006). But since emotional and moral acts indeed are mostly responses, it is crucial to pay close attention to the social and relational aspects of people's actions and selves.

\title{
Acknowledgements
}

I would like to thank Pekka Mäkelä for his useful comments on the previous version of this manuscript.

\author{
Address: \\ Simo Vehmas \\ Department of Education \\ P.O. Box 35 \\ 40014 University of Jyväskylä \\ Finland \\ E-mail: simo.vehmas@jyu.fi \\ Tel.: +358400247418
}

\section{References}

American Psychiatric Association (2000) Diagnostic and statistical manual of mental disorders. 4th ed. (DSM-IV). Washington, D.C.: American Psychiatric Association.

Aristotle (1998) Nicomachean Ethics. Trans. by David Ross. Oxford: Oxford University Press.

Arpaly, Nomy (2005) "How it is not 'just like diabetes': mental disorders and the moral psychologist". Philosophical Issues 15, 1, 282-298.

Barkley, Russell A. (2006) Attention-deficit hyperactivity disorder. 3rd ed. New York and London: Guilford Press.

Blair, James, A. A. Marsh, E. Finger, K. S. Blair, and J. Luo (2006) "Neuro-cognitive systems involved in morality". Philosophical Explorations 9, 1, 13-27.

Cohen, David (2006) "Critiques of the 'ADHD' enterprise”. In Critical New Perspectives on ADHD, 12-33. G. Lloyd, J. Stead, and D. Cohen, eds. London and New York: Routledge.

Cooper, Paul (2001) "Understanding ADHD: a brief critical review of literature". Children and Society 15, 1, 387-395.

Cullity, Garrett (2006) "As you were? Moral philosophy and the aetiology of moral experience". Philosophical Explorations 9, 1, 117-131.

Ehsleman, Andrew (2009) "Moral responsibility". In Stanford Encyclopedia of Philosophy. E. N. Zalta, ed. Stanford: The Metaphysics Research Lab. See http://plato.stanford.edu/ entries/moral-responsibility (accessed 2 December 2010).

Fine, Cordelia and Jeanette Kennett (2004) "Mental impairment, moral understanding and criminal responsibility: psychopathy and the purposes of punishment". International Journal of Law and Psychiatry 27, 5, 425-443.

Fischer, John M. (1999) "Recent work on moral responsibility". Ethics 110, 1, 93-139.

Fischer, John Martin and Ravizza Mark (1998) Responsibility and control: a theory of moral responsibility. Cambridge: Cambridge University Press.

Glannon, Walter (2005) "Neurobiology, neuroimaging, and free will". Midwest Studies in Philosophy 29, 68-82.

Goode, David A. (1984) "Socially produced identities, intimacy and the problem of competence among the retarded". In Special Education and Social Interests, 228-248. L. Barton and S. Tomlinson, ed. London: Croom Helm. 
Goodley, Dan and Mark Rapley (2001) "How do you understand 'learning difficulties'? Towards a social theory of impairment". Mental Retardation 39, 3, 229-232.

Goodley, Dan and Mark Rapley (2002) "Changing the subject: postmodernity and people with 'learning difficulties". In Disability/postmodernity: embodying disability theory,127-142. M. Corker and T. Shakespeare, ed. London and New York: Continuum.

Hacking, Ian (1995) Rewriting the soul: multiple personality and the sciences of memory. Princeton: Princeton University Press.

Kennett, Jeanette (2002) "Autism, empathy and moral agency". The Philosophical Quarterly 52, 208, 340-357.

Kennett, Jeanette (2006) "Do psychopaths really threaten moral rationalism?" Philosophical Explorations 9, 1, 69-82.

Maibom, Heidi L. (2008) "The mad, the bad, and the psychopath". Neuroethics 1, 3, 167-184.

Prinz, Jesse (2006) "The emotional basis of moral judgments". Philosophical Explorations 9, 1, 29 43.

Rapley, Mark and Charles Antaki (1996) "A conversation analysis of the 'acquiescence' of people with learning disabilities". Journal of Community and Applied Social Psychology 6, 3, 207227.

Schroeder, Timothy (2005) "Moral responsibility and Tourette syndrome". Philosophy and Phenomenological Research 71, 1, 106-123.

Shoemaker, David (2009) "Responsibility and disability". Metaphilosophy 40, 3-4, 438-461.

Strawson, Peter F. (1962) "Freedom and resentment". Proceedings of the British Academy 48, 1-25.

Tait, Gordon (2006) "A brief philosophical examination of ADHD". In Critical New Perspectives on $A D H D, 83-95$. G. Lloyd, J. Stead, and D. Cohen, eds. London and New York: Routledge.

Taylor, Steven J. (1996) "Disability studies and mental retardation". Disability Studies Quarterly 16, $3,4-13$.

Taylor, Steven J. and Robert Bogdan (1989) "On accepting relationships between people with mental retardation and non-disabled people: towards an understanding of acceptance". Disability, Handicap and Society 4, 1, 21-36.

Vehmas, Simo and Pekka Mäkelä (2009) "The ontology of disability and impairment: a discussion of the natural and social features". In Arguing about Disability: Philosophical Perspectives, 42-56. K. Kristiansen, S. Vehmas and T. Shakespeare, eds. London and New York: Routledge.

Watson, Gary (1996) "Two faces of responsibility". Philosophical Topics 24, 227-248.

Weithorn, Lois A. (2008) "Conceptual hurdles in the application of Atkins v. Virginia". Hastings Law Journal 59, 5, 1203-1234.

Williams, Bernard (2006) "The human prejudice”. In Philosophy as a humanistic discipline, 135152. A.W. Moore, ed. Princeton and Oxford: Princeton University Press. 